\author{
Bogdana Sybikowska \\ University of Warsaw
}

\title{
ARTICLE REVIEW \\ INTERNATIONAL POLITICAL AUTHORITY: ON THE MEANING AND SCOPE OF A JUSTIFIED HIERARCHY IN INTERNATIONAL RELATIONS (VOELSEN \& SCHETTLER, 2019)
}

DOI: $10.2478 /$ ppsr-2021-0007

ORCID no. 0000-0003-2743-0257

e-mail: bogdana.sybikowska@gmail.com

\begin{abstract}
This article is a review of a paper titled International political authority: on the meaning and scope of a justified hierarchy in international relations written by Daniel Voelsen and Leon Schettler. The growing power and authority of international organizations has been perceived by many as a sign of a new global order where the concept of sovereignty of the state is replaced with the constitutional principles of democracy, human rights and the rule of law. Recently, a tendency has been observed to consider international organizations as autonomous, legitimate institutions possessing political authority. However, it is rather challenging to find one and the complex understanding of political authority that encompasses all components that construct it. Voelsen and Schettler offer a detailed analysis of the concepts of international authority that are present in the literature and even criticize them. In this article, the conducted research is reviewed and scrutinized in detail.
\end{abstract}

Keywords: International authority, international organizations, legitimacy, global governance, global order

The growing power and authority of international organizations has been perceived by many as a sign of a new global order where the concept of sovereignty of the state is replaced with the constitutional principles of democracy, human rights and the rule of law. Recently, a tendency has been observed to consider international organizations as autonomous, legitimate institutions to possess political authority. The wide-ranging effects of globalization generate the "erosion" of state sovereignty, which can be explained by the transition of part of the functions traditionally reserved for states to other international actors (Van Staden, Vollaard 2002). This transition of authority has become a subject of multiple studies in the field of international relations and specifically global governance.

This article is a review of a paper titled International political authority: on the meaning and scope of a justified hierarchy in international relations by Daniel Voelsen and Leon Schettler. Voelsen is a doctor of political science and researcher at the German Institute for International and Security Affairs, and Schettler is an advisor on human rights protection mechanisms. The goal of their research was to analyze various concepts of international authority presented in the literature and consequently conclude about the essence of authority and when it is exercised in international relations. The choice of international 
authority as a theoretical lens serves the purpose of a factual identification of the basis for the functioning of numerous actors on the international arena. Unlike coercion, which is based on the actual use of force or a threat to use it, authority is based on a voluntary subordination. Thus, according to Voelsen and Schettler, if authority is not claimed by the entity, there is no foundation for normative relations and as a result authority cannot be exercised.

Authority is a key concept in the analysis of political processes. It is generally understood as "the right to rule" (Gerry 2011; Oeste 2012). In order to have a precise understanding of the concept, according to the authors of the paper, its normative nature and its functions have to be explored. The scope of authority relations is impressively broad. Nonetheless, Voelsen and Schettler believe that the preeminent social function of authority is a construction of our normative interactions with others through hierarchical coordination. Therefore, the central research question of the paper is whether and how various forms of international authority can be justified. The authors suggest that the conducted research may serve as a prelude to reflections on how various international organizations can be transformed into the autonomous sites of international authority and how we can achieve such a reform.

The article is well structured and divided broadly into five major parts. Voelsen and Schettler start by putting primary focus on the construing the broadly defined notion of authority and indicating the integrally normative nature of authority relations. On the other hand, the authors do not intend to create a new definition of authority, but instead base it on the existing conceptual grid, and proceed with the debate on international political authority. Voelsen and Schettler follow the declared structure and further discuss three interpretations of the concept of international authority, specifically the authority of international organizations according to Michael N. Barnett and Martha Finnemore, David Lake's relational authority and the concept of Michael Zürn's reflexive authority. In the final part of this article, the authors refer to the World Bank as an example of an international organization that possesses a considerable amount of power, but obstinately refuses to claim authority. The conclusion logically derives from theoretical considerations and from the case study presented in the last part of the article.

The title of the article, International political authority: on the meaning and scope of a justified hierarchy in international relations, suggests that the work would be dedicated to an examination of the patterns of hierarchical relationships between actors who exercise international authority and those on whom this authority is exerted. The authors focus instead on analyzing the content of international authority and arrive at the conclusion that, for the most part, international organizations do not exercise authority. According to Voelsen and Schettler, authority plays a very important role. Namely, it facilitates widely accepted and normatively justified forms of hierarchical coordination. However, the authors do not explain what is intended by the term which I consider to be crucial for the discussion. Coordination as such is generally believed to be a set of combined activities that are aimed to bring about a joint award (Zhong, Wonham 1990). It can be attained with an unguided activity among individuals (or states in our case). The main task of coordination is to achieve consistency in the work between all components by establishing rational connections (communication) between them. Hierarchical coordination consequently implies such an impact of a higher-level element on lower-level elements that forces the lower-level elements to act in concert. (Zhong, Wonham 1990). 
If there is a disagreement on any issues among two or more components, the conflict can be avoided by contacting a higher element in the hierarchy coordination level, so it can make a decision. International organizations (specifically those that have dispute settlement competencies) would serve as a perfect example of hierarchical coordination. That would make them "normatively justified" and prove that they can enjoy practical authority. Voelsen and Schettler, however, do not elaborate much on what is their understanding of the term and thus what would it mean for international organizations, its members and authority in this context.

Particularly noteworthy is the criticism of the formulated concepts of international authority developed by Barnett and Finnemore, Lake and Zürn. Barnett and Finnemore describe bureaucracies of international organizations that are characterized by administrative structures and formalistic procedures. They claim that by definition bureaucracies are authorities as they can use their institutional recourses "to induce deference from others". (Barnett, Finnemore 2004). David Lake focuses particularly on the authority relations that encompass states, international organizations (IOs) and even private actors. This kind of authority is based on a contract and thus is justified with it (Lake 2009). Zürn developed a concept of a reason-based authority, where a superior expertise of an entity justifies its authority (Zürn 2017). Voelsen and Schettler emphasize that while the aforementioned research presents a finished and empirically rich picture of the forms of epistemic authority overlooked so far in world politics, they ignore the normative aspect of the authority relations. According to them, this disregard results in a distorted picture of international relations overall.

Voelsen and Schettler are in favor of a narrower understanding of the concept of international authority. As stated in the article, Barnett and Finnemore, Lake and Zürn erroneously expand the concept of international authority with other forms of power. Therefore, according to Voelsen and Schettler, they mistakenly confuse the authority and power, which are quite similar, but substantially differ conceptually. The authors of the reviewed article arrive at the conclusion that the world needs more international authority, not less with all the instances of authority described by political philosophers so far being just regular manifestations of power. This is where the originality and innovation of this article comes from at the same time being the most controversial part of the paper that I will analyze further.

The authors put the primary focus on the normative aspect of authority relations. In fact, the normative condition discussed in the article can be conceptually translated into legitimacy. In this regard, Voelsen and Schettler specifically assert: “...this understanding of authority as a normative relation is synonymous with certain usages of the term 'legitimacy"' (Voelsen, Schettler 2019, p. 543). In other words, the debate is centered around the justifiability of authority. Consequently, the question that logically derives from the discussion is if authority should be claimed in order to be legitimate. The authors of the reviewed article specifically claim it should, holding that the key to a justified exercise of authority is a claim for the right to rule: "Those subjected to an exercise of power must believe it to be a justified exercise of the right to rule. When the entity exercising power, itself does not claim the right to rule, and indeed denies to rule, this is not possible" (Voelsen, Schettler, p. 550).

In the literature the discussion is present as a debate on "the nature of authority question" (Reglitz 2015). The conceptual core of authority is oftentimes described as the right to rule 
and there is no consensus among political philosophers on the normative standards (Zürn 2019, Dahl 1999; Buchanan and Keohane 2006), specifically as to if it is the claim right to rule or the power right to rule that should define the justifiability of authority. The claim right to rule indeed has an impact on normative relations between the authority and its subjects, which are quite democratic in their nature. However, decision-making on a global level is not always (and in most cases is not at all) democratic. These global institutions (international organizations) despite not being democratic can still be legitimate if they serve the purpose defined in the contract (for instance, a charter). Thus, political authority can be legitimate if it solves important problems for its subjects. It coordinates collective actions that enables complex social practices (hierarchical coordination), and many philosophers consider this to be an aspect that morally justifies international political authority (Raz 1985). Summing up, legitimacy has a relational character, which is defined by a perception of international organization's constituencies and observers (Zürn 2019). Moreover, Voelsen and Schettler almost conceptually equate legitimacy and authority, which are quite distinct in their nature. Therefore, I cannot agree with the argument presented in the reviewed paper that there are no instances of international authority among international organizations as they do not claim the authority. The authors rather argue that there are no examples of practical authority exercised by international organizations. However, their reasons to reject epistemic authority do not seem to be quite explicit.

Furthermore, an argument that the instances and sites of authority described in the research of Barnett and Finnemore, Lake and Zürn are rather the instances of power, not authority is disputable, as power does not necessarily imply that it is effective and make subjects comply with the orders, while authority does. Using a normative approach in their research, the authors overlook a sociological approach to legitimacy that can be extremely valuable when analyzing authority on the global level.

The article definitely meets the requirements of the scientific text. The authors demonstrate familiarity with the literature available on the matter and present conclusions that logically derive from the conducted analysis. In the abstract one can find the most important threads of the text, which is short, factual and concise. The authors also indicate the sources of financing, which is an important element as they reveal the contribution of scientific and research institutions in the creation of the research.

In Polish literature, scarcely any authors refer to the concept of international authority and this field is still under-explored. Available studies published in Western literature do not concentrate on international authority as part of the global governance, but rather analyze authority as being present on a national level only. In view of the above, I believe that the article is scientifically valuable and can serve as a basis for the future research efforts. One may agree or not with the opinion presented, but the authors undoubtedly originally reflect on the meaning of international authority and bring a new thread to existing concepts.

\section{References}

Barnett M. and Finnemore M. (2004), Rules for the World. International Organizations in Global Politics, Ithaca, NY: Cornell University Press.

Buchanan A., Keohane R. O. (2006), The Legitimacy of Global Governance Institutions, Ethics \& International Affairs, 20(4), 405-437. 
Dahl R. A. (1999), Can International Organizations be Democratic? A Skeptic's View, In I. Shapiro \& C.

Gerry K. (2011), 'We the People' and the Right to Rule: Democratic Authority and the Obligation to Obey the Law. SSRN.

Lake A.D. (2009), Hierarchy in International Relations, Ithaca, NY: Cornell University Press.

Oeste G. K. (2012), Legitimacy, Illegitimacy, and the Right to Rule: Windows on Abimelech's Rise and Demise in Judges 9, Bloomsbury Publishing USA.

Raz J. (1985), Authority and Justification, Philosophy and Public Affairs 14, 3-29.

Reglitz M. (2015), Political Legitimacy Without a (Claim-) Right to Rule, Res Publica 21, 291-307.

Voelsen D., Schettler L.V. (December 1, 2019), International Political Authority: On the Meaning and Scope of Justified Hierarchy in International Relations, International Relations 33, no. 4: 540-62.

Zürn M. (2017), From Constitutional Rule to Loosely Coupled Spheres of Liquid Authority. A Reflexive Approach, International Theory, 9(2), 261-85.

Zürn M., Tallberg J. (2019), The Legitimacy and Legitimation of International Organizations: introduction and framework, The Review of International Organizations (2019) $14,581-606$.

Zhong H, Wonham W. (1990), Hierarchical coordination, 8-14 vol. 1. 10.1109/ ISIC.1990.128432. 